\title{
Projeto de extensão Shantala: MASSAgem Para bebÊS
}

\section{Shantala Extension Project: Baby Massage \\ Proyecto de Extensión Shantala: masaje para bebés}

\author{
Arlete Ana Motter ${ }^{1}$ \\ Sacha Fernanda Sartor Porto ${ }^{2}$ \\ Ana Paula Micos ${ }^{2}$ \\ Tharcila Pazinatto da Veiga ${ }^{2}$ \\ Mônica Fernandes dos Santos ${ }^{2}$ \\ Karen de Souza Derussi ${ }^{2}$ \\ Indaiara Felisbino ${ }^{2}$ \\ Elisiane Krupniski \\ Camila Ollé da Luz Szklar²
}

\begin{abstract}
RESUMO
O Projeto de Extensão Shantala (massagem para bebês) tem o objetivo de estreitar os laços entre a família e o bebê, por meio da divulgação e aplicação da técnica em Centros de Educação Infantil de Matinhos/PR. O projeto possibilita a integração entre os fundamentos teóricos práticos (ensino), pesquisa e extensão, para estudantes do Curso de Fisioterapia da Universidade Federal do Paraná, Setor Litoral. O objetivo deste relato é descrever as atividades desenvolvidas no projeto de extensão no período de março a julho de 2010. Nesse período as atividades se concentraram em uma escola da rede pública de educação infantil, onde pais, cuidadores e bebês participaram de oficinas e de intervenções realizadas pela equipe do estudo. A experiência proporcionou a interação entre alunos e a comunidade e a vivência de resultados positivos como o relaxamento e a melhora do sono dos bebês, a importância da familiarização prévia às intervenções, o interesse da escola na continuidade do projeto e o prazer e satisfação das estudantes em participar da experiência. Por outro lado conviveram com dificuldades como local impróprio para aplicação da técnica, ruídos de outras crianças, baixa adesão de alguns pais e problemas em estabelecer vínculos com as crianças quando não foi possível um período de familiarização. Palauras-chave: massagem; bebês; educação em saúde; vínculo família-bebê.
\end{abstract}

\begin{abstract}
The Extension Project Shantala (baby massage) aims to strengthen ties between the family and baby, through the dissemination and application of the technique in Early Childhood Education Centres of Matinhos / PR. The project enables integration between the theoretical practical (teaching), research and extension, to students of Physiotherapy, from the Federal University of Parana, coastal sector. The purpose of this report is to describe the activities in the extension project in the period from March to July 2010. During this period the activities were concentrated in a public school early childhood education, where parents, caregivers and infants participated in workshops and interventions conducted by the study team. The experience provided the interaction between students and the community and experiencing positive results such as relaxation and improvement on infant sleep, the importance of familiarization prior to the interventions, the school's interest in continuing the project and the pleasure and satisfaction of students to participate in the experience. On the other hand they lived with difficulties as an inappropriate place for application of the technique, noise of other children, poor compliance of parents, problems in establishing ties with the children when it was not possible a familiarization period.

Keywords: massage; babies; health education; family-baby bond.
\end{abstract}

1 Professora Adjunta do Curso de Fisioterapia da Universidade Federal do Paraná.

2 Acadêmicas do Curso de Fisioterapia da Universidade Federal do Paraná. 


\section{RESUMEN}

El proyecto de extensión Shantala (masaje para bebés) tiene el objetivo de estrechar los lazos entre la familia y el bebé, por medio de la divulgación y aplicación de la técnica en Centros de Educación Infantil de Matinhos/PR. El proyecto posibilita la integración entre los fundamientos teoricos prácticos (enseñanza), pesquisa y extensión, para estudiantes del Curso de Fisioterapia de la Universidade Federal do Paraná, Setor Litoral. El objetivo de este informe es drescribir las actividades desarrolladas en el proyecto de extensión en el periodo de marzo a julio de 2010. En ese periodo las actividades concentráronse en una escuela de la red pública de educación infantil, donde padres, cuidadores, y bebés participaron de talleres y de intervenciones realizadas por el equipo de estudios. La experiéncia proporcionó la interación entre alumnos y la comunidad y la vivencia de resultados positivos como el relaxamiento y la mejora del sueño de los bebés, la importancia de la familiarización previa a las intervenciones, el interés de la escuela en la continuidad del proyecto y el placer y satisfacción de las estudiantes en participar de la experiéncia. Por otro lado convivieron con dificultades como sitio improprio para aplicación de la técnica, ruidos de otros niños, baja adhesión de algunos padres y problemas en establecer lazos con los niños cuando no fue posible un periodo de familiarización.

Palabras-clave: masaje; bebés; educación en salud; lazos familia-bebé.

\section{Introdução}

A Shantala é uma técnica de massagem para bebês que foi descrita inicialmente por Fréderick Leboyer, médico obstetra. Por volta dos anos 1970, Leboyer, andando pelas ruas do sul da Índia, avistou uma mulher sentada ao chão com seu bebê entre as pernas. Ficou encantado com a cena, observando a expressão singela do bebê e a concentração da mãe, formando um vínculo intensamente afetivo. Percebendo que massagear bebês é um costume da cultura local, o médico aprofundou-se no assunto, pesquisando sobre os efeitos fisiológicos da massagem.
Da pesquisa, surgiu um livro, colocando como título o nome da mãe observada inicialmente: Shantala (BRÊTAS, 1999).

Estudos comprovam a eficácia da massagem. $\mathrm{O}$ toque na pele do bebê estimula a percepção cutânea e acelera o crescimento psicomotor (VICTOR; MOREIRA, 2004). Efeitos sistêmicos abrangem os sistemas músculo-esquelético, nervoso e circulatório. A estimulação da digestão e do sistema respiratório também é alcançada com a Shantala (BRÊTAS ; SILVA, 1998; CRUZ ; CAROMANO, 2005). A criança relaxa e tem um sono mais tranquilo, diminui-se a ocorrência de cólicas e o vínculo entre mãe e bebê é aumentado, gerando um melhor desenvolvimento infantil (FIELD et al, 1996b, citado por ONOZAWA et al, 2001).

A massagem baseia-se no toque. Os atos de tocar e sentir são transmitidos fisicamente entre mãos, braços, pernas, tronco e pés, com contato direto sobre a pele. A mão do massageador deve estar aquecida, proporcionando o melhor contato com a pele do bebê. A massagem inicia com deslizamento das mãos sobre o peito, seguindo para braços, mãos, barriga, pernas, pés $e$, assim, costas. Por último, o rosto é massageado (VICTOR; MOREIRA, 2004). O toque terapêutico é uma prática milenar de imposição das mãos sobre o corpo. É muito utilizado por profissionais da saúde a fim de promover relaxamento, reduzir ansiedade, controlar dor, edema e outros efeitos (GOMES; SILVA ; ARAÚJO, 2008).

O Projeto de Extensão Universitário Shantala: massagem para bebês, é um projeto do Curso de Fisioterapia da Universidade Federal do Paraná, que se iniciou em março de 2009. A ideia do projeto surgiu a partir de uma oficina sobre cuidados com o bebê ministrada pela coordenadora do projeto no semestre anterior, no eixo Interações Culturais e Humanísticas, o qual faz parte do Projeto Político e Pedagógico da UFPR-Litoral. Está cadastrado na PROEC sob número 535/09. Inicialmente trabalhou-se para adequar o projeto às normas do Comitê de 
Ética em Pesquisa da própria universidade, tendo sido aprovado em agosto de 2009 sob o número 777.112.09.08. No primeiro ano do projeto o enfoque foi na elaboração de material didático e divulgação do método, fase em que participaram duas alunas bolsistas e três voluntárias. Neste segundo ano, além das oficinas, também foram introduzidas intervenções da massagem em crianças do ensino público de Matinhos/PR. No período descrito do projeto, contava-se com cinco alunas bolsistas e duas alunas voluntárias, que neste relato foram identificadas por número.

$\mathrm{O}$ presente estudo desenvolveu-se de março a julho de 2010, em um Centro de Educação Infantil (CEI) de Matinhos/PR. Todos os pais ou responsáveis do Berçario 1, que participaram da reunião inicial, foram convidados a autorizar a participação de seus filhos no protocolo de atendimento. Inicialmente foram incluídas dez crianças, porém duas delas apresentaram problemas de saúde e faltaram diversas vezes, sendo excluídas do protocolo. Participaram efetivamente oito bebês de ambos os sexos (4 meninas e 4 meninos), de idade entre 6 meses e 1 ano 5 meses, cujos pais assinaram um Termo de Compromisso Livre e Esclarecido, elaborado para esse estudo. A fim de garantir o sigilo em relação à identificação dos sujeitos do estudo, as crianças receberam nomes fictícios.

As oito crianças receberam oito aplicações da técnica Shantala. Entretanto, em seis lactentes foram realizadas quatro semanas de familiarização no berçário I, com o objetivo de favorecer o vínculo entre o acadêmico e o bebê. Dois bebês não participaram da familiarização devido à entrada tardia de uma das discentes no projeto, participando somente das aplicações da massagem.

\section{Desenvolvimento}

O Projeto de Extensão Shantala desenvolveu-se em quatro etapas. A primeira, dita familiarização, contemplou 4 semanas de vivência das estudantes na escola, com a finalidade de facilitar a interação acadêmica-bebê. Nesta etapa, as alunas basicamente brincavam com os bebês e auxiliavam na alimentação dos mesmos, permanecendo no CEI por cerca de duas horas em cada encontro.

Na segunda etapa, o projeto foi apresentado aos pais e cuidadores, que receberam uma cartilha, elaborada pelo grupo de extensionistas, sobre a técnica Shantala e orientação quanto à realização da massagem em domicílio. Nessa ocasião, cada criança foi avaliada com uma ficha de avaliação estruturada para a pesquisa, onde haviam informações a serem coletadas junto aos pais ou responsáveis.

A terceira etapa constituiu-se das oito intervenções realizadas no $\mathrm{CEI}$, uma ou duas vezes por semana, sendo atendidas sempre pela mesma acadêmica do projeto. Após cada aplicação da massagem, cada discente foi orientada a anotar suas próprias percepções sobre o desenrolar das atividades do projeto, desse modo favorecendo a coleta de dados qualitativos. $\mathrm{Na}$ quarta etapa do projeto de extensão, cada criança foi reavaliada e houve novo encontro com os pais ou responsáveis, pois deveriam questionar sobre a realização da massagem em domicílio, a observação de mudanças no comportamento dos filhos, alterações no desenvolvimento motor e padrão do sono do bebê.

Uma das acadêmicas, que não fazia intervenções atuou como observadora externa, também anotando suas percepções sobre as vivências do projeto. Esses dados junto às outras percepções e fichas de avaliação e reavaliação, permitiram que se refletisse sobre os pontos de fragilidades e pontos fortes do projeto. 
Pontos de Fragilidade

A acadêmica que não realizou o período de familiarização encontrou muita dificuldade em estabelecer vínculos com as crianças em quem aplicava a massagem. Nesse sentido, houve dificuldade em adquirir a confiança das crianças, conforme ela descreve: "Não participei das semanas de familiarização, pois entrei tardiamente no projeto. Esse foi o primeiro ponto que dificultou a aplicação da técnica nos bebês. Como não tive este primeiro contato, precisei, em toda sessão, conquistar e me aproximar das crianças" (Acadêmica 2). Diante de tal experiência, recomenda-se que, sempre que possível, prever um período inicial às intervenções destinado para as vivências com as crianças, que contemplem o lúdico favorecendo a relação terapeuta-bebê.

Quando trata-se da aplicação da massagem pelos familiares, esse problema não aparece, pois já existe um vínculo estabelecido e que poderá ser ampliado com a massagem. Também permite refletir sobre a frequência das intervenções, pois a dificuldade enfrentada pela aluna poderia ter sido minimizada se fossem aplicadas sessões diárias, pois para a criança se sentir segura e aproveitar mais esse toque, precisa-se de certo tempo adaptativo $e$ de certa frequência de realização da massagem (LEBOYER, 1995). Assim, se os pais também realizassem a massagem em domicílio, conforme orientação do projeto, provavelmente o bebê se adaptaria melhor ao toque, seja do familiar ou da acadêmica.

A aplicação do protocolo semanal foi prejudicado, em alguns casos, pela falta de assiduidade de algumas crianças, tendo como exemplo problemas de saúde de dois bebês e por alterações climáticas. No litoral do Paraná, especialmente na cidade de Matinhos os períodos chuvosos são longos. Não há proposição para resolver esses problemas, pois tanto os problemas de saúde apresentados, quanto alterações climáticas fogem ao controle dos pesquisadores.

Devido à limitação de espaço físico do CEI e a precária infraestrutura da escola, foi necessário realizar as intervenções na própria sala do berçário onde conviviam crianças atendidas pelo projeto $e$ crianças que não recebiam as intervenções. Sendo assim, no momento em que era realizada a massagem, haviam ruídos dos outros bebês e uma tentativa de chamar atenção das estudantes a todo momento, tornando-se um ambiente desfavorável para prender a atenção daqueles que recebiam a massagem.

O ideal seria ter um espaço reservado para que a massagem fosse feita individualmente, assim a criança não iria se dispersar com fatores adversos e poderia ficar ainda mais envolvida com a acadêmica, pois, segundo Figueiredo (2007) o "tocar" a criança pode ir além do próprio toque com as mãos, pode ser tocada com os olhos (observando atentamente a criança e suas necessidades), tocá-la com a voz (conversando com a criança), tocá-la com o corpo (a entrega recíproca), e, até mesmo tocá-la com o cheiro (o próprio perfume).

O CEI não oferecia ambiente climatizado (conforme preconiza o método Shantala), sala reservada para a execução das massagens e sala para reuniões com os pais, tais dificuldades podem ser ilustradas pelos relatos das acadêmicas:

\begin{abstract}
O pedido da mãe de não despir a criança devido ao frio dificultou a atividade, pois em alguns dias a massagem teve que ser realizada por cima da roupa ou colocando as mãos por baixo da vestimenta da criança. (Acadêmica 1)
\end{abstract}

A estrutura do local também foi um limitante porque é um ambiente pequeno, as salas não são devidamente aquecidas $e$ as crianças ficam 'amontoadas'. (Acadêmica 2) 
A solução poderia contemplar melhorias e ampliação do local, como construção de novas salas e implantação de climatizadores de ar, medidas estas que deveriam ser tomadas pelos órgãos gestores da escola. Nesse sentido, pretende-se apresentar os resultados do estudo ao Secretário Municipal de Educação do município, para que seja conscientizado das reais necessidades do CEI, no qual se realizou as intervenções.

Outra possibilidade seria encaminhar os bebês à Clínica Escola de Fisioterapia da UFPR-Litoral, onde seria possível o atendimento em ambiente mais adequado. Entretanto, não se sabe como seria a adesão de pais e responsáveis com a mudança de local.

$\mathrm{Na}$ percepções das alunas extensionistas, em alguns momentos, houve pouca colaboração por parte de algumas cuidadoras em distrair as crianças que não faziam parte do protocolo, tornando-se um fator limitante a aplicação da massagem pelas acadêmicas, conforme relato a seguir: "Houve um dia em que eu estava tentando iniciar a aplicação da massagem e a criança estava meio irritada. Uma das cuidadoras colocou uma música agitada e, em vez de auxiliar cuidando das outras crianças, pegou a Júlia no colo e disse: 'Não quer fazer Shantala hoje? Fica aqui dançando com a tia'. Nesse dia não houve aplicação, devido ao barulho e a atitude de não cooperação da cuidadora." (Acadêmica 2)

Há necessidade, portanto, de maior conscientização das cuidadoras sobre a importância de sua participação nesse processo de divulgação e promoção de saúde infantil. Outra possibilidade de solução seria a inserção de um aluno somente para interagir com as crianças que não recebem as intervenções.

A baixa adesão de alguns pais foi um ponto de fragilidade do projeto. Tal problema pode ter correlação com o horário dos encontros (final do horário da tarde), pois os pais e bebês estavam cansados e ansiosos em ir para casa. Como dito anteriormente, o local para as reuni- ões com os pais não eram adequados. Assim, o pai ou responsável ficava em pé com a criança no colo, enquanto recebia as informações das extensionistas, criando uma situação desconfortável. "... a dificuldade era em falar com alguns pais que não se mostravam muito interessados com o que eu tinha a dizer ou o que eu estava fazendo no local, sempre estavam com pressa." (Acadêmica 6).

Na continuidade do projeto, poderá ser necessário alterar o horário para divulgar a técnica e demonstrá-la, procurando abranger o coletivo dos pais, com o intuito de aumentar sua adesão. Também pretende-se conseguir sala própria para reuniões, seja no próprio $\mathrm{CEI}$, seja na UFPR - Litoral ou na Clínica Escola de Fisioterapia. Além disso, pretende-se atuar precocemente divulgando a massagem Shantala, em grupo de gestantes, pois verificou-se pela literatura (HOGA; REBERTE, 2006) que se a conscientização sobre a importância e benefícios da técnica for realizada durante o período gestacional, a adesão é maior no pós-parto, pois as mães iniciam a aplicação da massagem já nos primeiros meses de vida e a criança se adapta ao toque.

Os bebês maiores de 1 ano queriam brincar e correr pela sala, tornando o processo mais lento e complicado, como mostra o relato a seguir: "Como iniciei tardiamente a aplicação, acabei ficando com duas crianças com mais de 1 ano. Uma delas corria quando percebia que era hora da Shantala, fazendo gesto de 'não' com o dedinho. O tamanho também influenciou, porque era difícil colocar a criança na posição deitada em cima das pernas estendidas". (Acadêmica 2). Pela experiência do projeto, quanto antes se iniciam as primeiras aplicaçóes da Shantala, maior o vínculo estabelecido entre familiar-bebê ou entre acadêmico-bebê. Se as intervenções iniciarem até o terceiro mês de vida, conforme recomendação de Leboyer (1995), de maneira gradual a criança vai se adaptando à técnica. 


\section{Pontos fortes do projeto}

O período de familiarização (4 semanas) foi de grande importância para as intervenções posteriores, pois nesse período as acadêmicas interagiam com as crianças, com brincadeiras $e$ atividades lúdicas, até que se desenvolveu o binômio acadêmica-bebê.

Se por um lado houve diversas dificuldades ligadas à execução do projeto, por outro lado a experiência foi muito gratificante para todos os envolvidos. O contato com as crianças proporcionou a incrível sensação de relaxamento e serenidade, tanto para quem aplicou a massagem quanto para quem recebeu. Quem estava apenas olhando, observando cada gesto e cada sentimento, se encantou com o que viu. A vivência foi única, em cada sessão de Shantala se obtinha uma nova percepção e (re)conhecimento sobre o corpo humano.

Acredito que toda a experiência que vivi, tudo o que senti, é inexplicável e com certeza o fim desse trabalho envolveu muito mais que um simples papel com escritas. Esse trabalho resultou num despertar de cuidado e carinho pelo próximo por meio de um leve toque e um singelo sorriso, tive um verdadeiro crescimento como ser humano. (Acadêmica 3)

O carinhoso toque das acadêmicas, que passava tranquilidade e confiança aos bebês, criou importantes laços afetivos. A fascinação dos bebês pelas discentes era visível e cativava aos que compartilhavam do momento. "Marina ainda não anda e pouco engatinha. Sempre que eu chegava ao CEI, ela estava no chão e vinha até mim se arrastando com o bumbum, sabia que era hora da Shantala." (Acadêmica 1)
Cada movimento era percebido pela criança. Elas gostavam de atenção e da ideia de ter alguém ali, interagindo diretamente. Cada toque gerava um sorriso, um tanto desconfiado em princípio, mas que foi progredindo com o andar da experiência. A leve desconfiança permaneceu até que a ida das acadêmicas ao CEI tornou-se rotina e, então, todos ficavam ansiosos pela chegada da equipe do projeto.

\begin{abstract}
Notei que durante a massagem ela (a criança) gostou muito, ficava olhando bem atenta todos os movimentos e até tentou falar algumas palauras. Gostava quando eu tocava seu rosto e seus pés dava risadas e relaxava principalmente quando massageava o peito, braços $e$ mãos." (Acadêmica 1)
\end{abstract}

A vivência dentro do Centro de Educação Infantil foi de muita valia para a vida. As realizações que aconteceram nesse espaço não só contribuíram para o crescimento profissional, mas também para a vida (inter)pessoal. As cuidadoras, assim como as acadêmicas, perceberam diferenças nas crianças após as sessões. "As crianças melhoram muito nos dias de atendimento. Ficam mais calmas e tranquilas. Nos dias que não tem atendimento, elas ficam mais agitadas e se um bebê acorda, todos acordam. [...] Crianças que não conseguiam dormir ou dormiam pouco, agora ficam mais relaxadas a maior parte do tempo, graças à intervenção das meninas." (Relato de uma Cuidadora)

Os pais que realizaram a Shantala em casa, relataram que os bebês ficavam mais tranquilos após as massagens e dormiam melhor. Tal observação também foi descrita pelas extensionistas em suas percepções. Pais que se envolveram e demonstraram maior integração, participando das experiências, aprendendo $e$ aplicando as orientações em suas casas, proporcionaram benefícios tanto para si quanto para os bebês (SIMPSON, 2001). 
De maneira geral, o projeto Shantala contribuiu para a aproximação, o afeto, o carinho e a comunicação entre aqueles que cuidam, educam e compartilham do conjunto de métodos aplicados junto aos processos que ocorrem no desenvolvimento infantil.

A direção da escola prontamente acolheu a equipe do projeto e mesmo com poucos recursos, procurou viabilizar o que era possível, favorecendo a comunicação com os pais ou responsáveis. A receptividade foi tão positiva que motivou aos participantes do projeto a continuar desenvolvendo ações por um semestre a mais do período pretendido.

As acadêmicas do curso de fisioterapia desenvolveram-se tecnicamente durante esta experiência do projeto, pois tal qual o enfermeiro, o fisioterapeuta, no seu processo de formação acadêmica, deve passar obrigatoriamente pelo ensino teórico e pelo saber fazer (vivências práticas) que somente serão possíveis nos campos de estágio (SALOMÉ; ESPÓSITO, 2008) e em experiências proporcionadas por projetos de extensão. Também houve condições oportunas para o amadurecimento relativo a questões operacionais, características desse tipo de atividade que envolvem ações extensionistas.

Portanto, acredita-se estar favorecendo a integração do ensino-pesquisa e extensão, com a continuidade do projeto de extensão Shantala: massagem para bebês.

\section{Considerações finais}

O período de familiarização foi de suma importância para o bom desenvolvimento da técnica, pois a confiança expressa pelas crianças se deu graças a essa etapa. Tal constatação se deu pela dificuldade em criar vínculos com os bebês da acadêmica que não participou desse processo. As intervenções que iniciam nos primeiros meses de vida do bebê e realizadas com maior frequência semanal favorecem a adaptação ao toque terapêutico e o aumento do vínculo familiar ou acadêmico-bebê.

As intervenções foram essenciais para comprovar que a massagem Shantala exige um ambiente adequado (climatização, ambiente calmo e tranquilo) para sua realização. Assim, torna-se imprescindível a utilização de um local apropriado que ofereça o conforto necessário aos bebês e aplicadores, visando alcançar o relaxamento que a massagem promove. A aplicação da massagem envolve uma entrega de quem aplica e de quem recebe a massagem. Os pais que aderiram à prática da Shantala observaram seus benefícios para a saúde e tranquilidade dos bebês, o que também foi observado pelas alunas.

As atividades realizadas propiciaram a integração dos estudantes do Curso de Fisioterapia com a comunidade litorânea e favoreceram a integração do ensino-pesquisa e extensão. $\mathrm{O}$ projeto é viável, pois exige poucos recursos $e$ com alguns ajustes será possível continuar esse trabalho em outros centros de educação infantil do município ou com grupos de gestantes.

\section{REFERÊNCIAS}

BRÊTAS, J. R. S. A Arte de Massagear Bebês: A qualidade no Tocar. Acta Paul. Enf., São Paulo, v. 12, n. 2, p. 16-26, 1999

BRÊTAS, J. R. S.; SILVA, M. G. B. Massagem em bebês: um projeto de extensão comunitária. Acta Paul. Enf., São Paulo, v. 11, Número Especial, p. 59-63, 1998.

CRUZ, C. M. V. da; CAROMANO F. A. Características das técnicas de massagem para bebês. Rev. Ter. Ocup. Univ., São Paulo, v. 16, n. 1, p. 47-53, jan./abr., 2005.

FIGUEIREDO, B. Massagem ao bebê. Acta Portuguesa de Pediatria. Braga: 2007. p. 29-38.

GOMES, V. M.; SILVA, M. J.; ARAÚJO, E. A. C. Efeitos gradativos do toque terapêutico na redução da ansiedade 
de estudantes universitários. Rev. Bras. Enferm., Brasília, v. 61, n. 6, p. 841-846, nov.-dez. 2008.

HOGA, L. A. K.; REBERTE, L. M. Terapias corporais em grupos de gestantes: a experiência dos participantes. Rev. Bras. Enferm., v. 59, n. 3, p. 308-313, 2006.

LEBOYER, F. Shantala: uma arte tradicional massagem para bebês. 7 ed. São Paulo: Ground, 1995. 116p.

ONOZAWA, K. et al. Infant massage improves motherinfant interaction for mothers with postnatal depression. Journal of Affective Disorders, n. 63, p. 201-207, 2001.

VICTOR, J. F.; MOREIRA, T. M. M. Integrando a família no cuidado de seus bebês: ensinando a aplicação da massagem Shantala. Acta Scientiarum. Health Sciences, Maringá, v. 26, n. 1, p. 35-39, 2004.

SALOMÉ, G. M.; ESPÓSITO, V. H. C. Vivências de acadêmicos de enfermagem durante o cuidado prestado às pessoas com feridas. Reu. Bras. Enferm., Brasília, v. 61, n. 6, p. 822-827, nov./dez. 2008.

SIMPSON, Robbie. Baby massage classes and the work of the International Associatin of Infant Massage. Complementary Therapies in Nursing \& Midwifery, Leicester, v. 7, p. 25-33, 2001.

Texto recebido em 22 de setembro de 2010.

Texto aprovado em 10 de maio de 2011. 